\title{
Temporal and Spatial Variability in Metabolism of the Antarctic Pelagic Tunicate Salpa Thompsoni Foxton, 1961
}

Natalia losiphovna Minkina ( $\square$ niminkina@yandex.ru)

FSBIS A O Kovalevsky Institute of Biology of the Southern Seas of the Russian Academy of Sciences: FGBUN Federal'nyj issledovatel'skij centr Institut biologii uznyh morej imeni A O Kovalevskogo Rossijskoj akademii nauk https://orcid.org/0000-0003-3311-9801

Emest Zainullinovich Samyshev

FSBIS A O Kovalevsky Institute of Marine Biological Research of the Russian Academy of Sciences: FGBUN Federal'nyj issledovatel'skij centr Institut biologii uznyh morej imeni A O Kovalevskogo Rossijskoj akademii nauk

\section{Evgeny Pakhomov}

Fisheries and Oceans Canada

Victor Vladimirovich Melnikov

FSBIS A O Kovalevsky Institute of Biology of the Southern Seas of the Russian Academy of Sciences: FGBUN Federal'nyj issledovatel'skij centr Institut biologii uznyh morej imeni A O Kovalevskogo Rossijskoj akademii nauk

\section{Research Article}

Keywords: Southern Ocean, salps, respiration rates, diel variability, spatial and temporal heterogeneity

Posted Date: January 27th, 2022

DOI: https://doi.org/10.21203/rs.3.rs-1243247/v1

License: (c) (1) This work is licensed under a Creative Commons Attribution 4.0 International License. Read Full License 


\section{Abstract}

The weight-specific metabolic rates of the Antarctic pelagic tunicate Salpa thompsoni Foxton, 1961 were studied during March-April of 1998 and March 2002. The study revealed large variability in metabolic rates and attempted to explain the observed variability. The main factors driving variability, which were previously overlooked, included density of tunicates in incubation containers (incubation density), diel/circadian rhythms in salp ecophysiology, and spatial variability of their metabolic performance. The salp-specific respiration rates at $3^{\circ} \mathrm{C}$ were strongly negatively influenced by their incubation density ranging between 2.0 and $90.4 \mathrm{gWW} \cdot \mathrm{I}^{-1}$. The metabolism of both salp life forms (solitaries and aggregates) appeared to be independent of their body mass. At incubation densities of $3 \mathrm{gWW} \cdot \mathrm{I}^{-1}$, salps solitary and aggregate forms showed similar circadian rhythms in the respiration rates, with mean daytime and nighttime respiration rates of 79.5 and $41.5 \mu \mathrm{g} \mathrm{O}_{2} \cdot \mathrm{gWW}^{-1} \cdot \mathrm{h}^{-1}$ or $26.0 \%$ and $13.6 \%$ of the body carbon content, respectively. These specific respiration rates of S. thompsoni were assumed to be a "statistical norm" or climatology and were compared to actual field point observations during 1998 and 2002 near the Elephant Island, the South Orkney Islands, and the Bransfield Strait allowing calculating deviations from the "norm". This identified areas of the salp population either inhibition or successful performance that could be linked to the plankton community development and composition. The findings of this study highlighted the applicability of the metabolic theory in describing the salp ecological dynamics in the Southern Ocean.

\section{Introduction}

The pelagic tunicate, Salpa thompsoni, is an abundant and seasonally dominant metazoan inhabiting generally waters north of the Antarctic Polar Front (Foxton 1961). Since 1970s, this species has shown a southward shift in its distribution (Pakhomov et al. 2002; Atkinson et al. 2004). Resulting from this shift, salps began overlapping with the Antarctic krill, Euphausia superba, range, particularly south of the 60-th parallel, where a noticeable increase in the salp abundance had been observed (Atkinson et al. 2004). The latter is concerning because of salp high feeding activity within the similar to krill prey range (Harbison and Gilmer 1976; Anderson 1985; Minkina et al. 1999; Samyshev 2000a, b; Pakhomov et al. 2006).

Salps exhibit a complex life cycle and reproduction consisting of alternating generations of sexual (colonial forms, aggregates, or blastozoids) and asexual (single forms, solitaries, or oozoids) forms that differ morphologically (Foxton 1966). Similar to other tunicates (ascidians, pyrosomes, doliolids), salps can pump water through their internal cavity using their muscles creating water currents that salp use for propulsion, breathing, and feeding (Bone et al. 2000). While continuously swimming, salps deploy a feeding "mucus" net that catches a wide range of food particles. The food lumps are then passed to the stomach for digestion (Bone et al. 2000). This feeding method makes salps indiscriminate filterers, which may effectively capture particles as small as $1 \mu \mathrm{m}$ supporting high clearance, growth, development, and fertility rates allowing salps through sharp numerical "outbreaks" forming dense blooms (Harbison and Gilmer 1976; Deibel 1982; Anderson 1985).

According to our observations in 1997, in waters adjacent to the traditional krill fishing areas near the South Orkney Islands, salp concentrations in wet weight units, represented exclusively by S. thompsoni, exceeded those of the Antarctic krill by $>25$-fold (Samyshev et al. 1997). It was even greater during the followup survey in 1998 when the salp/krill biomass ratio on average was $>35$. The main accumulations of salps were confined to the waters influenced by the Antarctic Circumpolar Current explaining their separation from the krill maxima (Samyshev 2000a; Pakhomov et al. 2002; Lomakin and Samyshev 2004).

During the past decade, S. thompsoni biology, distributional shifts, seasonal variability in the population, and the spatio-temporal abundance patterns had received increasing attention (Foxton 1966; Samyshev 2000 a, b; Pakhomov et al. 2006; Bombosch 2008; Loeb and Santora 2011; Pakhomov and Hunt 2017; Henschke and Pakhomov 2019). Both stage-specific and population models of S. thompsoni had been developed (Henschke et al. 2018; Groeneveld et al. 2020). Nevertheless, there is still a paucity of studies investigating Antarctic salp metabolic rates and requirements.

Much of what we know about the functional characteristics of salps is based on research conducted in low to mid-latitudes as well as in the sub-Arctic (Ikeda 1974; Pavlova 1975; Abolmasova 1978; Cetta et al, 1986; Madin and Purcell 1992). These studies highlighted the high metabolic activity of pelagic tunicates (Madin and Deibel 1998). The first information on the respiration rates of S. thompsoni in the Southern Ocean was provided by Ikeda and Mitchell (1982), who performed 12 experiments, two of them with colonial forms, which was subsequently augmented by only a handful of experiments carried out by lkeda and Bruce (1986) and Reinke (1987). Relatively low metabolic values were obtained, which led to a conclusion that there are likely no differences in the metabolism of two salp life forms (Ikeda and Mitchell 1982; Ikeda and Bruce 1986; Reinke 1987). Our measurements carried out during the 3rd Ukrainian Antarctic Expedition (UAE) in austral early autumn 1998, used mainly solitary forms (35 experiments with oozoids and 4 with blastozoids), showed higher metabolic rates of solitary forms (Minkina and Samyshev 2004). The results of this expedition allowed for the first time to quantify salp trophic role in the pelagic ecosystem during salp blooms in the region of the complex hydrobiological setting (Minkina et al. 1999; Samyshev 2000a). These experiments were continued during the 7th UAE in 2002 and targeted mainly colonial (blastozooids) salp forms. The data collected during both expeditions allowed, on one hand, to carry out the quantitative inter-comparison of metabolic rates of $S$. thompsonilife forms and on another hand, to compare obtained values with previously published rates for other salp species. Considering a rapid salp expansion into the Antarctic krill habitat, it was imperative to identify the chokepoints of salp invasive populations. For this purpose, based on the metabolic theory we developed and applied the method based on the assessment of the salp "well-being" (or the statistical norm) in the survey area and compared it to field-measured metabolic rates (MR) to estimate the spatial variability in the metabolism of dominant zooplankton species (Minkina 2007; Minkina and Samyshev 2014).

It is known that the physiological state of poikilothermic organisms is strongly affected by their MR commonly measured in experiments. Studying the metabolic status of aquatic populations is challenging because it covers extended geographical areas with intricacies of high MRs variability at particular sampling points. To this day, the deployment of point measurements and the connection of its inherent "noisiness" to the larger geographical area is poorly understood that may have led to inaccurate interpolations (Brown et al. 2004; Kearney and Porter 2009; Allen and Polimene 2011; Barneche et al. 2014). Resulting from this, the applicability of the metabolic theory to the ecology of aquatic organisms is questioned by some researchers (Dodds et al. 2001; Tilman et al. 2004; Alcaraz 2016). In ecosystem studies, the spatial variability of aquatic organisms' MRs and their underlying causes remain largely 
unexplored. It is therefore still difficult to assess the total population impact on the pelagic habitat by abundant planktonic organisms, including tunicates. Furthermore, no less important is the solution of the inverse problem that is based on the assessment of the physiological state of abundant plankton populations that may inform the optimal sampling design to capture individual population contributions into the coherent whole community assessment. These are fundamental ecological issues that go beyond this study that also infringes on pollution and invasive species dynamics.

The main objective of this study was to identify the state of salp populations under different states of the Antarctic plankton community development. The paper's aims were twofold: first, to identify the main causes and mechanisms of the large variability in Antarctic salps metabolic values; and second, to assess the relationship between the community total metabolism and its autotrophic component.

\section{Materials And Methods}

Salps for metabolic measurements were collected during the 3rd and 7th Ukrainian Antarctic Expeditions (UAE) onboard the R.V. Ernst Krenke/ from March 26 to April 71998 in the vicinity of the Elephant (Mordvinov) and King George Islands as well as north of the South Orkney Islands, and onboard the R.V. Gorizont from March 11 to 18, 2002 in the Bransfield Strait. (Fig. 1). Specimens were collected in the near-surface (0-15 m) water layer using a conical plankton net with mouth area $\otimes 0.2 \mathrm{~m}^{2}$ equipped with the $3 \mu \mathrm{m}$ mesh and the 3 -I solid cod-end or from the surface using the scoop net. Undamaged and live individuals or short blastozoid chains (up to 5 specimens) without noticeable deviations from the natural behavior were used in the experiments. The chains were rather fragile and during the experiment often disintegrated into individuals. This did not affect the individual or chain condition and after the experiments measuring metabolic rates, the same organisms were successfully used in experiments to determine salp food rations (Minkina and Samyshev 2004). After the capture and before the experiment, captured animals were acclimated in 10-20 I aquariums filled with the $0.45 \mu \mathrm{m}$ filtered seawater for at least 12 hours. The cold rooms were set up for a constant experimental temperature ranging between 2 and $3{ }^{\circ} \mathrm{C}$. Salps were allowed to assimilate or egest accumulated in stomachs food and adapt to the limitation of living space (Minkina and Samyshev 2004). After acclimation, salps were transferred into 3-liter respirometers filled with filtered seawater.

Salp respiration rates were measured using a three-channel polarographic oximeter equipped with oxygen (Clark-type) and temperature sensors designed and manufactured by the Ocean MNTK MGI NASU (Youth scientific-technical collective «Ocean» of the Marine Hydrophysical Institute of the Ukrainian National Academy of Science) (Grekov et al. 2003). Sensors were calibrated daily by the Winkler method and the titration of samples was performed using a burette with graduation of $0.02 \mathrm{ml}$ and automatic zero setting. The duration of the experiments usually ranged from 4 to $18 \mathrm{~h}$, maximum - up to $26.5 \mathrm{~h}$ (Table 1 ). The incubation bottle content during experiments was mixed using magnetic stirrers. Every 30 seconds, a measurement of the oxygen concentration was saved into the sensor's internal memory (capacity up to 100 hours) and displayed on the monitor of the laptop. The frequency of observations and duration of the experiment allowed to (a) obtain statistically reliable data that can be smoothed and "filtered", (b) register the salp response to the stress and their acclimation to the conditions of the experiment, and (c) evaluate the diel variability in the salp breathing frequency. 
Table 1

Spatial variability of Salpa thompsoni energy metabolism rate in March-April 1998 and March 2002 . The temperature in the experiments is $3^{\circ} \mathrm{C}$; the live weigh

\begin{tabular}{|c|c|c|c|c|c|c|c|c|c|c|c|}
\hline \multirow[b]{2}{*}{$\begin{array}{l}\text { Experiment } \\
\#\end{array}$} & \multirow[b]{2}{*}{$\begin{array}{l}\text { Station } \\
\#\end{array}$} & \multirow[b]{2}{*}{$\begin{array}{l}\text { Latitude, } \\
{ }^{\circ} \mathrm{S}\end{array}$} & \multirow[b]{2}{*}{$\begin{array}{l}\text { Longitude, } \\
{ }^{\circ} W\end{array}$} & \multirow[b]{2}{*}{ Date } & & & & forms & & & \\
\hline & & & & & $\begin{array}{l}\text { Timing of } \\
\text { the } \\
\text { experiments, } \\
\mathrm{h}\end{array}$ & $\begin{array}{l}\text { Specimens } \\
\text { in the } \\
\text { experiment }\end{array}$ & $\begin{array}{l}\text { Average } \\
\text { body } \\
\text { length } \\
L, \mathrm{~mm}\end{array}$ & $\begin{array}{l}\text { Average } \\
\text { wet } \\
\text { weight } \\
\text { W, g }\end{array}$ & $\begin{array}{l}\text { Concentration } \\
\text { of wet weight } \\
\text { in the } \\
\text { experiment } \\
C_{w} \mathrm{~g} \cdot \mathrm{I}^{-1}\end{array}$ & $\begin{array}{l}\text { Average } \\
\text { respiration } \\
\text { rate during } \\
\text { the } \\
\text { experiment } \\
R, \mu g \\
\mathrm{O}_{2} \cdot \text { ind }^{-1} \cdot \mathrm{h}^{-1}\end{array}$ & $\begin{array}{l}\text { Respiratı } \\
\mu \mathrm{g} \mathrm{O}_{2} \cdot \mathrm{g}- \\
\text { with } \\
\text { variable } \\
C_{w}\end{array}$ \\
\hline 1 & 2 & 3 & 4 & 5 & 6 & 7 & 8 & 9 & 10 & 11 & 12 \\
\hline \multicolumn{12}{|c|}{ I-Survey near the Elephant Island (1998) } \\
\hline 1 & 7 & 61.13 & 55.82 & 26.03 & $7.75-10.25$ & 1 & 55 & 5 & 3.86 & 524.6 & 104.9 \\
\hline 2 & 8 & 61 & 55.87 & 27.03 & $17-24.25$ & 1 & 49 & 4 & 3.09 & 836.3 & 209.1 \\
\hline 3 & 8 & 61 & 55.87 & 27.03 & $18,12-19,75$ & 1 & 62 & 6 & 11.24 & 504.8 & 84.1 \\
\hline 4 & 8 & 61 & 55.87 & 27.03 & $7.5-16.62$ & 1 & 63 & 6 & 4.64 & 225.01 & 37.5 \\
\hline 5 & 1 & 61.4 & 56.47 & 27.03 & $23.5-34$ & 1 & 70 & 8 & 15.04 & 267.55 & 33.44 \\
\hline 6 & 12 & 60.83 & 56.2 & 28.03 & $13.5-18.42$ & 1 & 72 & 3.8 & 2.93 & 359.95 & 94.72 \\
\hline 7 & 12 & 60.83 & 56.2 & $\begin{array}{l}28- \\
29.03\end{array}$ & $21.67-35.58$ & 1 & 71 & 6.3 & 11.80 & 296.84 & 47.12 \\
\hline 8 & 12 & 60.83 & 56.2 & 28.03 & $14-16.42$ & 1 & 72 & 3.8 & 2.93 & 154.06 & 40.54 \\
\hline 9 & 12 & 60.83 & 56.2 & $\begin{array}{l}28- \\
29.03\end{array}$ & $22.58-35.58$ & 1 & 71 & 6.3 & 11.80 & 60.9 & 9.67 \\
\hline 10 & 12 & 60.83 & 56.2 & 29.03 & $13.63-20.33$ & 1 & 70 & 5.5 & 15.30 & 149.76 & 27.23 \\
\hline 11 & 12 & 60.83 & 56.2 & 29.03 & $13.5-19.83$ & 1 & 73 & 5.7 & 42.44 & 44.68 & 7.84 \\
\hline 12 & 12 & 60.83 & 56.2 & $\begin{array}{l}29- \\
30.03\end{array}$ & $21.58-33.08$ & 1 & 67 & 6.8 & 26.86 & 34.66 & 5.1 \\
\hline 13 & 12 & 60.83 & 56.2 & $\begin{array}{l}29- \\
30.03\end{array}$ & $21.58-33.08$ & 1 & 24 & 0.8 & 5.75 & 5.89 & 7.36 \\
\hline \multicolumn{12}{|c|}{ II - Survey near the South Orkney Islands (1998) } \\
\hline 15 & 15 & 59.52 & 44.95 & 30.03 & $10.42-17.92$ & 1 & 72 & 7.8 & 14.66 & 149.3 & 19.14 \\
\hline 16 & 15 & 59.52 & 44.95 & 30.03 & $12.5-17.92$ & 1 & 66 & 7.6 & 30.11 & 27.89 & 3.67 \\
\hline 18 & 15 & 59.52 & 44.95 & $\begin{array}{l}31.03- \\
1.04\end{array}$ & $24.83-35.5$ & 1 & 56 & 6.2 & 24.43 & 20.48 & 3.3 \\
\hline 19 & 15 & 59.52 & 44.95 & 31.03 & $1.33-10.5$ & 1 & 28 & 1.2 & 8.65 & 14.89 & 12.41 \\
\hline $14 a$ & 15 & 59.52 & 44.95 & 30.03 & $10.25-18.3$ & 2 & 50.5 & 2.55 & 14.17 & 19.56 & 7.67 \\
\hline 17 & 24 & 59.5 & 46.02 & 31.03 & $8.75-10.7$ & 1 & 82 & 12.8 & 9.94 & 125.5 & 9.8 \\
\hline 20 & 24 & 59.5 & 46.02 & 31.03 & $13-18.25$ & 1 & 24 & 0.8 & 5.75 & 22.68 & 28.35 \\
\hline 21 & 24 & 59.5 & 46.02 & 31.03 & $13.13-18.17$ & 1 & 67 & 7.3 & 28.89 & 122.61 & 16.8 \\
\hline 22 & 24 & 59.5 & 46.02 & 31.03 & $13.13-18.17$ & 1 & 100 & 17.4 & 33.30 & 293.81 & 16.89 \\
\hline 23 & 24 & 59.5 & 46.02 & 31.03 & $20.5-23.5$ & 1 & 47 & 3.3 & 24.14 & 80.17 & 24.29 \\
\hline 24 & 24 & 59.5 & 46.02 & 31.03 & $19.5-0.12$ & 1 & 55 & 3.4 & 90.43 & 25.37 & 7.46 \\
\hline 25 & 24 & 59.5 & 46.02 & 31.03 & $19.75-23.5$ & 1 & 66 & 6.1 & 24.03 & 62.98 & 10.32 \\
\hline 26 & 24 & 59.5 & 46.02 & $\begin{array}{l}31.03- \\
1.04\end{array}$ & $1.37-11.45$ & 1 & 50 & 3.0 & 21.90 & 29.21 & 9.74 \\
\hline 27 & 24 & 59.5 & 46.02 & $\begin{array}{l}31.03- \\
1.0\end{array}$ & $1.2-14.47$ & 1 & 54 & 5.1 & 5.59 & 65.11 & 21.7 \\
\hline
\end{tabular}




\begin{tabular}{|c|c|c|c|c|c|c|c|c|c|c|c|}
\hline 28 & 24 & 59.5 & 46.02 & $\begin{array}{l}31.03- \\
1.0\end{array}$ & $1.25-14.42$ & 1 & 56 & 5.1 & 20.01 & 24.46 & 4.8 \\
\hline 29 & 24 & 59.5 & 46.02 & 01.04 & $15.42-20.58$ & 1 & 57 & 3.8 & 10.52 & 77.27 & 20.33 \\
\hline 30 & 24 & 59.5 & 46.02 & 01.04 & $15.08-18$ & 1 & 50 & 3.3 & 12.86 & 192.53 & 58.34 \\
\hline $31 a$ & $62-1$ & 59 & 43.02 & 02.04 & $0.17-13$ & 4 & 72.8 & 7.7 & 9.69 & 18.41 & 2.39 \\
\hline 32 & $62-1$ & 59 & 43.02 & 02.04 & $0.17-13$ & 1 & 74 & 7.7 & 12.27 & 300.54 & 39.03 \\
\hline $33 a$ & $62-1$ & 59 & 43.02 & 02.04 & $0.25-13$ & 4 & 75.8 & 6.9 & 8.73 & 143.62 & 20.81 \\
\hline 34 & $62-1$ & 59 & 43.02 & 02.04 & $15-23.17$ & 1 & 71 & 8.2 & 13.86 & 178.12 & 21.72 \\
\hline 36 & $62-1$ & 59 & 43.02 & 02.04 & $16.72-20.5$ & 1 & 70 & 7.5 & 20.98 & 77.55 & 10.34 \\
\hline 37 & $62-1$ & 59 & 43.02 & $\begin{array}{l}02- \\
03.04\end{array}$ & $20.33-36$ & 1 & 68 & 7.3 & 12.32 & 65.99 & 9.03 \\
\hline 38 & $62-1$ & 59 & 43.02 & 03.04 & $0.5-6.75$ & 1 & 60 & 4.3 & 11.92 & 66.87 & 15.55 \\
\hline 39 & $62-1$ & 59 & 43.02 & 03.04 & $13.25-20.75$ & 1 & 71 & 7.7 & 21.55 & 122.96 & 15.97 \\
\hline \multicolumn{12}{|c|}{ III - in the vicinity of the King George Island (1998) } \\
\hline 40 & $66-1$ & 62.4 & 59.19 & $6-7.04$ & $22.08-27.67$ & 1 & 47 & 3 & 21.13 & 35.44 & 11.81 \\
\hline 41 & $66-1$ & 62.4 & 59.19 & $6-7.04$ & $21.83-25.42$ & 1 & 42 & 1.7 & 12.29 & 42.74 & 25.14 \\
\hline 42 & $66-1$ & 62.4 & 59.19 & $6-7.04$ & $22-26$ & 1 & 25 & 0.4 & 9.85 & 7.8 & 19.5 \\
\hline 44 & $67-1$ & 62.32 & 58.59 & 07.04 & $11.2-13$ & 1 & 22 & 0.8 & 5.75 & 52.82 & 66.02 \\
\hline $43 a$ & $67-1$ & 62.32 & 58.59 & 07.04 & $10.85-20.58$ & 6 & 65.5 & 4.5 & 8.54 & 121.66 & 27.04 \\
\hline \multicolumn{12}{|c|}{ IV - Survey in the Bransfield Strait (2002) } \\
\hline $1 \mathrm{a}$ & 44 & 63.57 & 60.67 & 12.03 & $11.67-17.92$ & 1 & 75 & 7.8 & 2.44 & 230.4 & 29.54 \\
\hline $2 a$ & 44 & 63.57 & 60.67 & 12.03 & $11.67-17.00$ & 2 & 78 & 6.1 & 4.13 & 350 & 57.38 \\
\hline $3 a$ & 44 & 63.57 & 60.67 & $\begin{array}{l}12- \\
13.03\end{array}$ & $19.5-33$ & 1 & 75 & 7.8 & 2.44 & 234.67 & 30.09 \\
\hline $4 a$ & 44 & 63.57 & 60.67 & $\begin{array}{l}12- \\
13.03\end{array}$ & $19.5-33$ & 2 & 78 & 6.1 & 4.13 & 210.37 & 34.49 \\
\hline $5 a$ & 44 & 63.57 & 60.67 & $\begin{array}{l}12- \\
13.03\end{array}$ & $20-33$ & 6 & 69 & 6.24 & 3.90 & 131.67 & 21.12 \\
\hline $6 a$ & 47 & 63.32 & 60.33 & $\begin{array}{l}13- \\
14.03\end{array}$ & $13.5-32$ & 7 & 55.14 & 6.24 & 5.28 & 36.13 & 14.97 \\
\hline $7 a$ & 52 & 63.32 & 60 & $\begin{array}{l}13- \\
14.03\end{array}$ & $17.5-32$ & 3 & 40 & 2.097 & 1.97 & 148.47 & 70.8 \\
\hline $8 a$ & 52 & 63.32 & 60 & $\begin{array}{l}14- \\
15.03\end{array}$ & $10.5-37$ & 7 & 85.29 & 5.929 & 12.97 & 85.39 & 14.4 \\
\hline $9 a$ & 23 & 63.2 & 61.45 & 16.03 & $8.25-14.37$ & 5 & 24.2 & 0.28 & 2.57 & 12.12 & 43.3 \\
\hline 10 & 33 & 63.4 & 61.21 & 17.03 & $14.37-23$ & 2 & 82 & 12.72 & 3.975 & 333.6 & 26.23 \\
\hline 11 & 33 & 63.4 & 61.21 & 17.03 & $14.37-23$ & 2 & 90.5 & $16 . .8$ & 10.23 & 588.24 & 35.91 \\
\hline 12 & 33 & 63.4 & 61.21 & 17.03 & $14.33-23$ & 2 & 85 & 13,89 & 8.68 & 276.91 & 19.94 \\
\hline
\end{tabular}

At the end of incubations, total salp body lengths were measured with an accuracy of $1 \mathrm{~mm}$ and their displacement volume was determined using a Yashnov voluminometer by titration on a burette with graduation of $0.1 \mathrm{ml}$ (Kisselev 1969). Then salps were weighed on a pharmaceutical balance with an accuracy of $10 \mathrm{mg}$. A total of 51 respiration rate experiments of Salpa thompsoni were performed using 39 oozoids and 12 blastozoids. To standardize the literature data, salp respiration values were adjusted to $3^{\circ} \mathrm{C}$ using $Q_{10}$ obtained by Ivleva (1981) for Coelenterata: 2.13 for the temperature range $20-15^{\circ} \mathrm{C}, 2.20$ for $15-10{ }^{\circ} \mathrm{C}$, 2.27 for $10-5{ }^{\circ} \mathrm{C}$. We assumed that $1 \mathrm{mg} \mathrm{O}$ corresponds to $0.3 \mathrm{mg}$ carbon (Vinberg 1960). After Anninsky and Schepkina (2004), the S. thompsoni dry mass accounted for $2 \%$ of the wet mass and carbon mass was $0.22 \%$ of the wet mass.

To quantify the temporal and spatial variability of salp in situ respiration rates, we aimed to adjust respiration rates to the experimental density of incubated salps. Recent studies have shown that the level of the respiration of aquatic organisms during in vitro incubations is strongly influenced by the volume of the incubation container, which is a function of the organism density (life weight concentration) in respirometers. The density-dependent regulations of physiological functions led to changes in behavioral reactions and inhibition of vital processes by produced metabolites (Schwarz et al. 1976; Khailov and Popov 1983; Boaden 1989; Minkina and Pavlova 1995; Khailov et al. 1999). The above contributes to variable traditionally not accounted for but should not be ignored. 
It was found that with an increase in the organism experimental density $\left(\mathrm{C}_{\mathrm{w}}\right)$, the specific respiration rates in different groups of aquatic organisms' decline (Khailov and Popov 1983; Minkina and Pavlova 1995; Khailov et al. 1999; Glazier 2006):

$C_{W}=N * W / V,(1)$

where $\mathrm{N}$ is the number of organisms in the respirometer, $\mathrm{W}$ is the wet bodyweight of the individual, $\mathrm{V}$ is the volume of the respirometer. This dependence is much stronger than the traditionally studied body mass effects on respiration rates. Indeed, the exponents in correlations describing these two types of dependences vary in the range from -0.2 to -0.25 for the body mass and from -0.6 to -0.9 (Fig. 2b) for the organism experimental density (Khailov and Popov 1983; Popov 1987; Khailov et al. 1999).

Another factor that can significantly affect the value of energy metabolism is the diel (or circadian) rhythms of physiological processes and behavior of aquatic organisms. The daily respiration rhythms can be estimated by conducting experiments over the 24-hour cycle (Samyshev 2002; Minkina and Pavlova 1995). However, the experimental determination of the diel respiration pattern in aquatic organisms is associated with several logistical difficulties: multiple experiments over a 24-hour cycle with similarly sized organisms at the multi-day stations. This is not always possible in the field.

We have adopted an approach that involves using the specific respiration rates of different sized salps normalized by the constant mass concentration (Co), which was chosen to be close to the minimum value in the range. In our case, Co was set to $3 \mathrm{gWW} \cdot \mathrm{l}^{-1}$ (Fig. 2b). The values were calculated using the following formula:

$R_{o} / W=R / W *\left(C_{W} / C_{o}\right) b 1,(2)$

where $C_{0}$ is the constant value of mass concentration selected for the analysis, $C_{w}$ is the experimental mass concentration, $R_{0} / W$ is the mass-specific respiration at $C_{0}, R / W$ is the measured value, $b 1$ is the exponent and $a_{1}$ is the constant according to regression $R / W=a_{1} * C_{w}-b 1$.

Thus, the specific respiration rate in experiments at a constant temperature is a function of the live mass concentration, individual body weight, and time of day and the method deployed here allowed the analysis and comparison of results obtained in a variety of conditions. Considering the relationship between the respiration intensity and body weight $\left(R / W=a_{2} * W^{-b 2}\right)$, the $R_{0} / W$ values are recalculated for the average individual weight $W_{a v}$ in the selected size classes of organisms as follows:

$R^{\prime} / W=R_{0} / W *\left(W / W_{a v} \cdot\right)^{-b 2},(3)$

where R'/ W is the mass-normalized specific respiration intensity. After normalization, values belonging to respiration dynamics obtained at different points of the studied area can be used to distinguish the diel trend (procedure of the spatial averaging). For each hour of the 24-hour cycle, normalized respiration rate values were averaged at hourly intervals over the entire surveyed polygon providing diel respiration pattern for a given species or a life form (procedure of the time averaging). The average daily metabolic rate was then calculated from the 24 -h pattern and was taken as a "statistical norm" (R '/ W $100 \%$ ). Furthermore, the residual between the survey average $\left(R^{\prime} / W_{\text {av }}\right.$.) during time interval T of implementation of the experiment in different stations grid nodes from the average for the same time on the temporal trend selected for all polygon on the whole (according to a circadian rhythm for the time of the experiment) (R' / $\mathrm{W}_{\mathrm{T}}$ ) divided by the statistical norm $\left(\mathrm{R}^{\prime} / \mathrm{W}_{100 \%}\right.$ ) would allow calculating a deviation $\Delta$ (in \%) from average results representative of the population performance affected by the ecosystem status:

$\Delta=\left(\mathrm{R}^{\prime} / \mathrm{W}_{\mathrm{av}} \cdot-\mathrm{R}^{\prime} / \mathrm{W}_{\mathrm{T}}\right) / \mathrm{R}^{\prime} / \mathrm{W}_{100 \%}(4)$

The deviations from the obtained "norms", calculated at the station grid nodes, make it possible to construct their distribution fields and compare them to various oceanographic and biological characteristics. We believe that the method of biological monitoring outlined above allows obtaining new information necessary for an objective assessment of the population status of zooplankton species of interest in natural conditions.

\section{Results And Discussion}

Figure 2a shows total length-mass relationships of solitary and aggregate salps, as well as both forms combined used in our experiments performed during two expeditions, while mass-specific respiration rates as a function of the salp experimental density are presented in Fig. $2 \mathrm{~b}$. For comparative purposes, Fig. $2 \mathrm{~b}$ also includes previously published relationships. The wide range of respirometer volumes and salp sizes used in our experiments allowed obtaining the values ranging from 2.0 to $90.4 \mathrm{gWW} \cdot \mathrm{I}^{-1}$. The data from Pavlova (1975) included two species of salps from the Mediterranean Sea with experiments conducted at $20^{\circ} \mathrm{C}$ (and adjusted to $3^{\circ} \mathrm{C}$ ) with $\mathrm{C}_{\mathrm{w}}$ ranging from 0.017 to $9 \mathrm{gWW} \cdot \mathrm{l}^{-1}$ (Fig. 2b). Finally, recalculated data from Ikeda (1974) summarized the relationship obtained for six tunicate species (five species of salps and one species of pyrosomes) in the tropical Pacific with $\mathrm{C}_{\mathrm{w}}$ varying between 0.7 and 20 gWW $\cdot I^{-1}$. It appears that mass-specific respiration rates of subtropical and tropical tunicates are in good agreement with our data for aggregate salps. The exponents are -0.84 for solitary and -0.91 for aggregate salps (Fig. 2b). The exponents for the correlations of the mass-specific respiration rates and individual body mass are -0.09 and -0.06 , respectively (Fig. 3b), indicating that mass-specific respiration rates of salps are almost independent of the body mass. As shown earlier, the dependence of the mass-specific rates of metabolism on the salp unit mass concentration has proven to be stronger than the traditional correlation with the individual body mass (Minkina and Samyshev 2004). It is noteworthy that the mass-specific respiration rates of $S$. thompsoni aggregates had a weaker relationship with the salp unit mass in comparison to solitary forms. 
Table 2

Correlations for the rate $(R)$ and specific rate $(R / W)$ of respiration of salps and some tunicates and their wet weight $(W)$, according to our own and literature data recalculated for a temperature of $3^{\circ} \mathrm{C}$

\begin{tabular}{|c|c|c|c|c|c|c|}
\hline Source & Species & $\begin{array}{l}\text { Temp., } \\
{ }^{\circ} \mathrm{C}\end{array}$ & $\begin{array}{l}\text { Numb. } \\
\text { meas. }\end{array}$ & $\begin{array}{l}\text { Wet weight range } \\
W, \mathrm{~g}\end{array}$ & $\begin{array}{l}R, \mu \mathrm{O}_{2} / \\
\text { (ind·h), } \\
R / W, \mu \mathrm{O}_{2} / \\
(\mathrm{g} \cdot \mathrm{h})\end{array}$ & $\begin{array}{l}\text { Coef. of } \\
\text { correlation } r^{2}\end{array}$ \\
\hline \multirow{8}{*}{$\begin{array}{l}\text { Ikeda (1974) } \\
\text { five species of } \\
\text { tunicates }\end{array}$} & Thalia democratica & 17.3 & 3 & \multirow[t]{4}{*}{$0.1-5.86$} & $R=5.23 W^{0.68}$ & 0.972 \\
\hline & Salpa fusiformis & 17.3 & 2 & & $R_{0}=5.94 W^{0.93}$ & \multirow{2}{*}{0.964} \\
\hline & $\begin{array}{l}\text { Pegea confederata } \\
\text { (solitaries) }\end{array}$ & 25.7 & 3 & & $\begin{array}{l}R / W=5.23 W \\
-0.32\end{array}$ & \\
\hline & & & & & $\begin{array}{l}R_{0} / W=5.94 \\
W^{0.071}\end{array}$ & 0.137 \\
\hline & S. fusiformis & 17.3 & 4 & $0.1-4.53$ & $R=6.71 \mathrm{~W}^{0.46}$ & 0.733 \\
\hline & lasis zonaria & 27 & 1 & & $R_{0}=0.28 \mathrm{~W}^{1.00}$ & 0.956 \\
\hline & Pyrosoma vericilatum & 25.7 & 2 & & $\begin{array}{l}R / W=6.71 \\
W^{-0.54}\end{array}$ & 0.790 \\
\hline & (aggregate) & & & & $\begin{array}{l}R_{0} / W=5.54 \\
W^{-0.0025}\end{array}$ & 0.0001 \\
\hline \multirow[t]{4}{*}{ Pavlova (1975) } & Salpa democratica, & 20 & 20 & $0.005-$ & $R=6.95 W^{0.39}$ & 0.658 \\
\hline & Salpa maxima & & & 0.33 & $R_{0}=6.29 W^{0.96}$ & 0.891 \\
\hline & & & & & $\begin{array}{l}R / W=6.95 W \\
-0.62\end{array}$ & 0.828 \\
\hline & & & & & $\begin{array}{l}R_{0} / W=7.46 W \\
0.25\end{array}$ & 0.254 \\
\hline Abolmasova (1978) & $\begin{array}{l}\text { S. maxima } \\
\text { S. democratica }\end{array}$ & $\begin{array}{l}15.2- \\
15.6\end{array}$ & 17 & $0.011-0.1$ & $R=10.81 W^{0.975}$ & - \\
\hline \multirow{4}{*}{$\begin{array}{l}\text { Ikeda and Mitchell } \\
\text { (1982) }\end{array}$} & S. thompsoni & -1.1 & 12 & $2.25-11$ & $R=4.4-12.4$ & - \\
\hline & S. thompsoni, & $-1,1$ & 12 & average 5.7 & $R=2.29 W^{0.74}$ & 0.972 \\
\hline & Ihlea racovitzei & & 4 & $0.4-11$ & & \\
\hline & $\begin{array}{l}\text { (solitaries, } \\
\text { two aggregate specimens) }\end{array}$ & & & average 1.5 & & \\
\hline \multirow[t]{8}{*}{ Cetta et al. (1986) } & S. fusiformis, & 16.5 & 15 & $0.5-7.2$ & $R=6.85 W^{0.68}$ & 0.89 \\
\hline & aggregate & & & & & \\
\hline & S. fusiformis & 16.5 & 10 & $2.1-20.8$ & $R=14.4 W^{1.15}$ & 0.95 \\
\hline & solitary & & & & & \\
\hline & S.maxima & 24.5 & 16 & $1.3-14.2$ & $R=14,63 W^{1.22}$ & 0.88 \\
\hline & $\begin{array}{l}\text { aggregate, the specimens were with the filled } \\
\text { intestines }\end{array}$ & & & & & \\
\hline & S. maxima, & 24.5 & 9 & $0.1-5.9$ & $R=6.43 W^{1.04}$ & 0.87 \\
\hline & aggregate & & & & & \\
\hline $\begin{array}{l}\text { Madin and Purcell } \\
\text { (1992) }\end{array}$ & Cyclosalpa bakeri & 11 & 27 & $0.01-0.1$ & $R=13.3 W^{1.16}$ & 0.92 \\
\hline \multirow[t]{2}{*}{$\begin{array}{l}\text { Igushi and lkeda } \\
(2004)\end{array}$} & S. thompsoni, & $1.0-1.7$ & 6 & $1.45-63.7$ & $\begin{array}{l}R / W=1.132 W \\
-0.15\end{array}$ & 0.99 \\
\hline & solitary & Av. 1.3 & & & & \\
\hline
\end{tabular}




\begin{tabular}{|c|c|c|c|c|c|c|}
\hline Source & Species & $\begin{array}{l}\text { Temp., } \\
{ }^{\circ} \mathrm{C}\end{array}$ & $\begin{array}{l}\text { Numb. } \\
\text { meas. }\end{array}$ & $\begin{array}{l}\text { Wet weight range } \\
W, g\end{array}$ & $\begin{array}{l}R, \mu g \mathrm{O}_{2} / \\
\text { (ind } / \mathrm{h}), \\
R / W_{1} \mu \mathrm{g} \mathrm{O}_{2} / \\
(\mathrm{g} \cdot \mathrm{h})\end{array}$ & $\begin{array}{l}\text { Coef. of } \\
\text { correlation } r^{2}\end{array}$ \\
\hline & S. thompsoni, & $1.0-1.7$ & 25 & $0.35-27.65$ & $\begin{array}{l}R / W=0.89 W \\
-0.03\end{array}$ & 0.94 \\
\hline & aggregate & Av. 1.3 & & & & \\
\hline \multirow[t]{8}{*}{ Our data } & S. thompsoni, & 3 & 41 & $0.4-17.4$ & $R=21.96 W^{0.91}$ & 0.36 \\
\hline & solitary & & & & $\begin{array}{l}R_{0}=49.07 \mathrm{~W} \\
1.04\end{array}$ & 0.57 \\
\hline & & & & & $\underset{-0.09}{R / W=22.21 \mathrm{~W}}$ & 0.006 \\
\hline & & & & & $\begin{array}{l}R_{0} / W=49.07 W \\
0.04\end{array}$ & 0.0016 \\
\hline & S. thompsoni, & 3 & 13 & $0.28-6.24$ & $R=30.72 W^{0.75}$ & 0.40 \\
\hline & colonial & & & & $\begin{array}{l}R_{0}=25.77 \mathrm{~W} \\
1.07\end{array}$ & 0.78 \\
\hline & & & & & $\begin{array}{l}R / W=30.72 W \\
-0.25\end{array}$ & 0.065 \\
\hline & & & & & $\begin{array}{l}R_{0} / W=25.77 W \\
0.07\end{array}$ & 0.014 \\
\hline
\end{tabular}

For meaningful comparisons, only mass-specific respiration rates normalized by the constant concentration were used. For all mass-specific respiration rates, the basic concentration of $\mathrm{gWW} \cdot \mathrm{I}^{-1}$ was employed as given in the formula (2). The specific respiration rate results against salps' wet mass are shown in Fig. $3 \mathrm{~b}$ and presented in Table 1. The table summarizes the respiration rate regressions as a function of the individual body mass presented in comparable units and adjusted for temperature differences in experiments. The correlation coefficients show that the data scattering (Fig. $3 \mathrm{~b}$ ) significantly decreased as compared to that in Fig. 3a. A similar tendency can be observed in the results of calculations using the live mass concentration according to Ikeda (1974) and Pavlova (1975) (Table 2 and Fig. 3b). It appears that temperature and mass adjusted values from tropics to polar regions are broadly comparable. However, the values for the tropical Pacific tunicates, according to lkeda (1974), were slightly lower. The data by lkeda and Mitchell (1982) for S. thompsoni obtained in the temperature range -0.5 to $+1.8^{\circ} \mathrm{C}$, were also below values obtained in our study (Fig. 3a, Table 2). This discrepancy seems to be due to both the interspecific differences and the possible inhibition of tunicate activity in their habitat before catching.

After correcting the mass-specific respiration rates of Antarctic salps for the experimental concentration and individual body mass of specimens, it became possible to delineate variability associated with the time of the day. This allowed us, for the first time, to assess the circadian rhythm of the mass-specific respiration rates of both solitary and aggregate forms of $S$. thompsoni (Fig. 4, Table 3). Both forms showed similar diel respiration patterns, but solitary forms had nearly double mass-specific respiration rates compared to aggregate forms (Fig. 4). The lowest respiration rates in both life forms of $S$. thompsoni were observed in the morning hours 4:00-5:00. The highest or elevated values in oozoid's respiration were observed in the evening (18:00-22:00), at night (23:0024:00) and midday (11:00-15:00), while the aggregate's respiration picked in the evening (20:00) and before the noon (11:00). The average metabolic rates calculated for the salp density in respirometers equal to $3 \mathrm{gWW} . \mathrm{I}^{-1}$, irrespective of the individual body mass, were 79.5 and $41.5 \mu \mathrm{g} \mathrm{O}_{2} \cdot \mathrm{g}^{-1} \cdot \mathrm{h}^{-1}$ in oozoids and blastozoids, respectively (Table 3). These values are taken as the statistical "norms" (or as 100\%) for the salp forms in our further calculations. 
Table 3

Diurnal variability of the specific energy metabolism rate $\left(R_{\mathrm{T}} / \mathrm{W}, \mu \mathrm{g} \mathrm{O} \mathrm{O}_{2} \cdot \mathrm{g}^{-1} \mathrm{WW} \cdot \mathrm{h}^{-1}\right)$ in the Antarctic salp Salpa thompsoni during March-April 1998 and March 2002. The temperature in the experiments is $3^{\circ} \mathrm{C}$ and $C_{0}=3 \mathrm{~g}^{-1}$ wet weight $\cdot \mathrm{I}^{-1}\left(\mathrm{~N}=\right.$ sample size, $\sigma=$ standard deviation, $\mathrm{t}_{\mathrm{a}}=$ $90 \%$ confidence interval)

\begin{tabular}{|c|c|c|c|c|c|c|c|c|}
\hline \multirow[t]{2}{*}{ Time of day } & \multicolumn{4}{|c|}{ Solitary salps } & \multicolumn{4}{|c|}{ Aggregate salps } \\
\hline & $R_{\mathrm{T}} / W_{\mathrm{av}}$ & $\mathbf{N}$ & $\sigma$ & $t_{a}$ & $R_{\mathrm{T}} / W_{\mathrm{av}}$ & $\mathbf{N}$ & $\sigma$ & $t_{a}$ \\
\hline 0:00 & 132.4 & 22 & 158.4 & 55.5 & 38.5 & 6 & 39.7 & 26.6 \\
\hline $1: 00$ & 58.6 & 26 & 52.3 & 16.9 & 34.5 & 6 & 34.1 & 22.9 \\
\hline $2: 00$ & 64.2 & 21 & 110.7 & 39.7 & 51.7 & 7 & 56.9 & 35.4 \\
\hline 3:00 & 75.2 & 19 & 89.4 & 33.7 & 45.4 & 7 & 39.9 & 24.8 \\
\hline 4:00 & 37.7 & 17 & 35.7 & 14.2 & 27.4 & 7 & 24.5 & 13.4 \\
\hline 5:00 & 33.9 & 17 & 32.8 & 13.1 & 22.8 & 7 & 19.8 & 12.3 \\
\hline $6: 00$ & 55.6 & 21 & 64.3 & 23.1 & 18.9 & 7 & 17.5 & 10.9 \\
\hline 7:00 & 50.6 & 18 & 57.7 & 22.4 & 21.4 & 7 & 16.7 & 10,4 \\
\hline 8:00 & 62.9 & 19 & 52.6 & 19.8 & 25.4 & 7 & 19.3 & 12.0 \\
\hline 9:00 & 43 & 20 & 41 & 15.1 & 19.8 & 5 & 19.7 & 14.5 \\
\hline $10: 00$ & 39 & 13 & 24.5 & 11.2 & 38.0 & 3 & 60.5 & 57.4 \\
\hline 11:00 & 87.8 & 7 & 137.9 & 85.7 & 88.2 & 7 & 89.5 & 55.7 \\
\hline $12: 00$ & 52 & 8 & 39.3 & 22.9 & 29.2 & 8 & 27.5 & 16.0 \\
\hline $13: 00$ & 104.7 & 19 & 104.2 & 39.3 & 58.0 & 8 & 42.8 & 24.9 \\
\hline $14: 00$ & 91.1 & 21 & 93.9 & 33.7 & 43.3 & 6 & 31.5 & 21.2 \\
\hline $15: 00$ & 88.5 & 18 & 93.6 & 36.3 & 39.6 & 8 & 38.4 & 22.3 \\
\hline $16: 00$ & 61.6 & 25 & 77.4 & 25.5 & 32.3 & 9 & 24.9 & 13.7 \\
\hline $17: 00$ & 73.4 & 29 & 91.9 & 28.1 & 33.0 & 10 & 36.0 & 18.7 \\
\hline 18:00 & 150.5 & 24 & 148.2 & 49.8 & 52.8 & 5 & 32.0 & 23.5 \\
\hline 19:00 & 107.1 & 24 & 108.6 & 36.5 & 26.2 & 4 & 18.4 & 15.1 \\
\hline $20: 00$ & 68.8 & 19 & 56.1 & 21.2 & 96.4 & 7 & 78.3 & 48.7 \\
\hline $21: 00$ & 125.5 & 12 & 166.9 & 79.2 & 65.0 & 6 & 110.3 & 74.1 \\
\hline $22: 00$ & 106.6 & 21 & 181.7 & 65.2 & 65.1 & 8 & 73.6 & 42.8 \\
\hline $23: 00$ & 136.5 & 23 & 190.4 & 65.3 & 23.5 & 6 & 18.2 & 12.2 \\
\hline \multirow[t]{2}{*}{ Average daily values } & 79.5 & 463 & 33.6 & 11.3 & 41.5 & 161 & 20.8 & 7.0 \\
\hline & \multicolumn{4}{|l|}{ (“norm”) } & \multicolumn{4}{|l|}{ ("norm”) } \\
\hline
\end{tabular}

Based on the obtained data set (Table 1), we have constructed maps of the spatial variability in S. thompsoni energy metabolism (EM) near the South Orkney and Elephant Islands (Fig. 5, insert) and in the Bransfield Strait (Fig. 6, insert). In 1998, positive deviations of salp EMs (Table 1, Fig. 5f) were observed in the dynamically active area near Elephant Island. A fragment of the cyclonic meander of the Southern branch of the Antarctic Circumpolar Current (ACC), which contained the Weddell Sea waters, was registered in this area (for details see Lomakin and Samyshev 2004). The flow width was 20-25 miles, and the surface velocity reached $40-50 \mathrm{~cm} \cdot \mathrm{s}-1$. In this area, there was the greatest abundance of salps ever recorded here, mostly oozoids with concentrations of up to 120 gWW'm ${ }^{-3}$ (Lomakin and Samyshev 2004) (Fig. 5d). The maximum specific rate of EM here was 2.8 times higher (with a deviation of 184\%) as compared with the "statistical norm" in the southwestern part of the surveyed area. This area coincided with very low phytoplankton biomass (15-190 $\left.\mathrm{mg} \bullet \mathrm{m}^{-3}\right)$ indicative of the active grazing of salps (Fig. 5e).

The water dynamics north of the South Orkney Islands was set by a wavy meander flowing around the islands with a powerful anticyclonic topographic gyre observed about 200 miles north of them. It was formed through the interaction of the Southern branch of ACC with the Peary Seamount, which suggests the quasi-stationary and topographic nature of this gyre (Lomakin and Samyshev 2004). The maximum salp concentrations (up to $32 \mathrm{gWW} \cdot \mathrm{m}^{-3}$ ) were observed in the central part of the warm topographic gyre directly above the Peary Seamount (Lomakin and Samyshev 2004). This was accompanied by the lowest phytoplankton concentrations $\left(13.5 \mathrm{mg} \bullet \mathrm{m}^{-3}\right)$ and minimum EM values $(\sim-25 \%)$ (Table 1, Fig. 4c). In the southeastern part of this area, where salp biomass was the lowest, the phytoplankton concentration reached $1200 \mathrm{mg} \cdot \mathrm{m}^{-3}$, and the EM rates were close to the "statistical norm" (-4\%) (Fig. $\left.5 \mathrm{~b}\right)$. 
Inhibition of the salp population, e.g. negative deviations of EM rates from the "statistical norm", was also observed in early autumn 2002 in the Bransfield Strait (Fig. 6). In the western part of the strait, there were sharp seabed troughs with a depth of up to $1000 \mathrm{~m}$ compared to the general average depth of about 200-300 m. This area is also characterized by the highly indented coastline and the presence of numerous islands (Artamonov et al. 2003). Such geography favors the stagnated eddy formation resulting in the long-term accumulation of salps potentially creating food shortages (Fig. 6a). In the center of the quasistationary gyre situated in the middle of the Bransfield Strait, the maximum salp concentrations reaching $2.89 \mathrm{gWW} \cdot \mathrm{m}^{-3}$ of salps were observed. They decreased towards the periphery of the gyre to $1.42 \mathrm{mgWW} \cdot \mathrm{m}^{-3}$. Salp biomass strongly negatively correlated to the phytoplankton standing stock, 22.7 $\mathrm{mg} \cdot \mathrm{m}^{-3}$ vs $788 \mathrm{mg} \cdot \mathrm{m}^{-3}$ in the center and outside the gyre respectively (Fig. $6 \mathrm{~b}$ ). Indeed, negative salp EM values (up to $-70 \%$ ) coincided with the center of the gyre, indicating the inhibition of salps' activity likely due to the food shortage. At the periphery of the gyre and beyond it, the salp performance appeared to be at the "statistical norm" (see inserts in Fig. 6a, b).

According to our calculations, the energy costs in the experiments at $3^{\circ} \mathrm{C}$ with the live mass concentration of $3 \mathrm{gWW} \cdot \mathrm{I}^{-1}$ in the whole range of sizes accounted for $26.0 \%$ and $13.6 \%$ of the body carbon content in solitary and aggregate salps, respectively. For S. fusiformis from the tropical Atlantic in the temperature range $13.5-19.5^{\circ} \mathrm{C}$, the similar demands accounted for $21.3 \%$ and $9.7 \%$ of the body carbon in oozoids and blastozoids, respectively (Cetta et al. 1986 ). However, the daily energy expenditures in solitary S. cylindrica at $24^{\circ} \mathrm{C}$ in the same work was $\sim 99 \%$. High scatter in the results may be due to the speciesspecific energy costs linked to the minimum nutritional needs of salps. For example, for the Mediterranean $S$. fusiformis at $16^{\circ} \mathrm{C}$, the daily food requirements averaged $107-117 \%$ of the body carbon content (Cetta et al. 1986). For comparison, the daily food needs of $S$. thompsoni calculated from the stomach pigment fluorescence accounted for 5-75\% of their body carbon contents (Pakhomov et al. 2002; 2006).

Earlier we discussed possible mechanisms behind the effect of organisms' density on the specific respiration rates in aquatic organisms (Minkina and Pavlova 1995; Minkina 2007). It is known that a universal regulator of chemical reactions rates is the concentrations of reactants. The regulation of rates of biological processes through the concentration of biomaterial appears to be a manifestation of the same law (Khailov et al. 1999). When we assess the respiration intensity of salps at $3{ }^{\circ} \mathrm{C}$ at various salp concentrations (Fig. $2 \mathrm{~b}$ and according to formula (2)) for solitaries with the respirometer salp densities 2.93-90.43 $\mathrm{gWW}^{-1}$ daily respiration rates would have accounted for $26.5-1.5 \%$ of their body carbon content. The same was true for the blastozooids: $1.97-$ 14.17 $\mathrm{gWW}^{-1}$ and 19.9-3.2\% carbon content accordingly. Currently, density effects of the metabolic rates for salps were not well studied although feeding rates of gelatinous invertebrates could be affected by the volume of, and thus the animal density in, the incubation container (Scolardi et al. 2006). Unlike salps and other marine invertebrates (e.g. Minkina and Pavlova 1995; Khailov et al. 1999), experiments with the Antarctic krill did not confirm the reduction in their respiration rates at increasing densities in a large (105 I) flow-through respirometer (Swadling et al. 2005). Nevertheless, it has been proposed that krill school density may impact school oxygen concentrations and thus krill respiration rates (Brierley and Cox 2010).

The lack of studies of the density effects may be due to the adoption of the physiological rules of larger animals (fish, mollusks, large crustaceans) for the zooplankton organisms. In small invertebrates, the basal metabolism covers the minimal energy needs and is measured using stationary and starved animals (Vinberg 1956). The basal metabolism can subsequently be used to assess minimal food requirements. The routine metabolism (often considered to be higher than the basal metabolism because organisms are not stationary) is generally measured using organisms that have restricted, due to the experimental setup, movements. While routine metabolism is often used as the total metabolism, the latter should include both basal and active metabolism that accounts for the organisms' active movement (Vinberg 1956). It appears that in the majority of experiments to estimate routine metabolism there are no regulations about the density of organisms in incubation chambers and it is chosen subjectively by the individual researchers. This leads to highly variable outcomes that allow building regressions between metabolic rates and experimental temperature likely leading to erroneous results if the density of organisms is not considered. The introduction of respirometers with polarographic sensors allowing to monitor continuously the incubation container oxygen concentrations (Samyshev 2002; Minkina and Pavlova 1995) helped to address the issue of handling stress, organism adaptation to the experimental conditions, and the animal behavior during the experiment (Samyshev et al. 1980), which is impossible to disentangle in the classical Winklers' end-point measurement method. For example, the respiration rate measurements of $S$. thompsoni at $-1.9--2.0^{\circ} \mathrm{C}$ in the lkeda and Bruce (1986) experiments yielded very low (2.3-2.8\% of body C) daily respiration demands. It is not clear if such low metabolic needs are driven by the very low experimental temperature (it is clear at the lowest range of this species tolerance, Foxton (1966)) or high organism density in the experimental containers, or both (Ikeda and Bruce 1986).

\section{Conclusions}

The main causes of large variability in the specific rate of S. thompsoni metabolism in March-April 1998 and 2002 were threefold. One of the main reasons (traditionally not considered) for the significant variability in respiration rates related to the salp density in respirometers is likely related to the cumulative interactive effects of individuals during the experiment. It appears that in the aggregate forms of $S$. thompsoni, the dependence of the specific respiration on the salp concentration is weaker than in solitary forms. At the same time, the specific metabolism rate of both forms is nearly independent of their body weights.

Another factor that can significantly affect the salp metabolism is the circadian rhythm in the physiological processes and behavior of the animals. For the first time, we have documented the circadian rhythm in the specific rates of the $S$. thompsoni respiration for the solitary and aggregate forms. While different in absolute levels, both forms have demonstrated similar rhythms of the diurnal respiration rate with the maximum during the nighttime hours. This is likely a result of active diel ascent/descent and feeding activities. It is noteworthy that the salp gut fluorescence does not show a clear diel pattern, yet $S$. thompsoni are strong migrators and concentrate near the surface at night for feeding and possibly reproduction (Pakhomov et al. 2002; Pakhomov 2004).

Finally, the large dispersion in the specific respiration rates of $S$. thompsoni was correlated to the spatial variability of their energy metabolism affected by the surrounding pelagic environment. Furthermore, it is plausible that the vector and magnitude of deviation of the energy metabolism (EM) rates in salps in the oceanic zone, in favorable physical and chemical conditions, depend on the phytoplankton supply. Salps are known to have one of the highest feeding rates

Page $10 / 19$ 
among planktonic heterotrophs (Samyshev 2000a; Minkina et al. 1999). The salience of this dependence in salps is due to the extremely high intensity of their feeding, which is an order of magnitude higher than the feeding activity of other abundant planktonic heterotrophs (Minkina et al. 1999; Samyshev 2000a, b; Pakhomov et al. 2002). The positive "response" of the population of salps (positive deviations of the metabolism rates) has been observed in the dynamically active zones, e.g. one found in the vicinity of the Elephant Island. Negative deviations in the population metabolism and observed potential food shortage both point to the salp being effective grazers capable of shaping the pelagic community development. It is possible that the food scarcity during the winter and early-spring would be major factors driving salp population development. Southern Ocean warming and associated ice retreat may thus promote salp further southward expansion (Atkinson et al. 2004).

The findings of this study are important both for the understanding of the self-regulation mechanisms in the Antarctic plankton communities, including the invasion of salps to high latitudes as well as for the correction of the budget calculations for the organic matter and energy fluxes in the Antarctic region. The results obtained also confirm the applicability of the metabolism theory in the ecology of hydrobionts.

\section{Declarations}

Acknowledgments. The work was carried out within the framework of Scientific Research Programs of Russian Academy of Sciences "Comprehensive studies of the current state of the ecosystem of the Atlantic sector of the Antarctic" \# AAAA-A19-119100290162-0, "Functional, metabolic and toxicological aspects of the existence of aquatic organisms and their populations in biotopes with different physicochemical conditions" \# № 0556-2021-0003.

Funding: The study was funded by the Russian Academy of Sciences under two grants: "Comprehensive studies of the current state of the ecosystem of the Atlantic sector of the Antarctic", Grant \# AAAA-A19-119100290162-0, and "Functional, metabolic and toxicological aspects of the existence of aquatic organisms and their populations in biotopes with different physicochemical conditions", Grant \# 0556-2021-0003.

Conflict of Interest: The authors declare they have no conflict of interests.

Data availability: Data archiving is not mandated but data will be made available on reasonable request.

Author's Contribution: NIM and EZS participated in the expeditions, conducted measurements, analyzed the data and prepared the first Russian draft of the manuscript, VVM and EAP translated the manuscript and significantly contributed to the MS writing. All authors approved the final version of the MS.

\section{References}

1. Abolmasova GI (1978) The exchange rate in some species of invertebrates from the Mediterranean Sea. Sea Biology. Naukova Dumka Publishers, Kiev, pp 25-29. (In Russ.)

2. Alcaraz M (2016) Marine zooplankton and the metabolic theory of ecology: is it a predictive tool? J Plankton Res 38:3:762-770. https://doi.org/10.1093/plankt/fbw012

3. Allen Jl, Polimene L (2011) Linking physiology to ecology: towards a new generation of plankton models. J Plankton Res 33:989-997. https://doi.org/10.1093/plankt/fbr032

4. Anderson V (1985) Filtration and ingestion rates of Salpa fusiformis Cuvier (Tunnicata: Thaliacea): effects of size, individual weight and algal concentration. J Exp Mar Biol Ecol 87:13-29. https://doi.org/10.1093/plankt/fbr032

5. Anninsky BE, Schepkina AM (2004) Organic composition of Salpa thompsoni salpa from the South Antarctic region. Monitoring Systems of Environment: Tools, models, monitoring: Scientific Proc. Sevastopol: 281-285. (In Russ.)

6. Artamonov YuV, Romanov AS, Vnukov YuL, Perov AA, Stepura II (2003) The results of oceanographic research in the western part of the Bransfield Strait in March 2002. Ukrainian AntarcticJournal1:7-16(In Russ.)

7. Atkinson A, Hill SL, Pakhomov E, Siegel V, Anadon R, Chiba S, Daly KL, Downie R, Fielding S, Fretwell P, Gerrish L, Hosie GW, Jessop MJ, Kawaguchi S, Krafft BA, Loeb VJ, Nishikawa J, Peat HJ, Reiss CS, Ross RM, Langdon B, Quetin LB, Schmidt K, Steinberg DK, Subramaniam RC, Tarling GA, Ward P (2004) KRILLBASE: a circumpolar database of Antarctic krill and salp numerical densities, 1926-2016. Earth Syst Sci Data 9:193-2107. https://doi:10.5285/8b00a915-94e3-4a04-a903-dd4956346439

8. Barneche D, Kulbicki M, Floeter S, Friedlander A, Maina J, Allen AP (2014) Scaling metabolism from individuals to fish communities at broad spatial scales. Ecol Lett 17:1067-1076. https://doi.org/10.1111/ele.12309

9. Boaden PJS (1989) Adaptation of intertidal sand meiofaunal oxygen uptake to temperature and population density. Sci Mar 53 2-3:329-334. http://scimar.icm.csic.es /scimar/index.php/secld/6/ldArt/2510/. Accessed 10 October 2020

10. Bone Q, Carre C, Ryan KP (2000) The endostyle and the feeding filter filter in salps (Tunicata). J Mar Biol Ass UK 80:523-534

11. Bombosch A (2008) Euphausia superba or Salpa thompsoni - who is going to win? https://www. coolantarctica.com. Accessed 11 October 2020

12. Brierley AS, Cox MJ (2010) Shapes of krill swarms and fish schools emerge as aggregation members avoid predators and access oxygen. Curr Biol 20:1758-1762

13. Brown JH, Gillooly JF, Allen AP, Savage VM, West GB (2004) Toward a metabolic theory of ecology. Ecology 85:1771-1789. https://doi.org/10.1890/039000

14. Cetta CM, Madin LP, Kremer P (1986) Respiration and excretion by oceanic salpa. Mar Biol 22:529-537. https://doi.org/10.1007/BF00392605

15. Deibel A (1982) Laboratory determined mortality, fecundity and growth rates of Thalia democratica Forskal and Dolioletta gegenbauri Uljanin (Tunicata, Thaliacea). J Plankt Res 4:1:143-152. https://doi.org/10.1093/plankt/4.1.143

Page $11 / 19$ 
16. Dodds PS, Rothman DH, Weitz JS (2001) Re-examination of the '3/4-law' of metabolism. J Theor Biol 209:9-27. https://doi.org/10.1006/jtbi.2000.2238

17. Foxton $P$ (1961) Salpa fusiformis Cuvier and related species. Discovery Rep 34:D1-116

18. Foxton $\mathrm{P}$ (1966) The distribution and life history of Salpa thompsoni Foxton with observation on a related species, Salpa gerlachei Foxton. Discovery Rep 21:4:1-116

19. Glazier DS (2006) The 3/4-power law is not universal: evolution of isometric, ontogenetic metabolic scaling in pelagic animals. Bioscience 56:325-332. DOI: 10.1641/0006-56[325:TPLINU]2.0.C0;2

20. Grekov NA, Minkina NI, Samyshev EZ (2003) Automated multichannel oximeter for ecological and physiological studies. Monitoring Systems of Environment: Collection of scientific researches. Sevastopol, pp 44-47 (In Russ.)

21. Groeneveld Y, Berger U, Henschke N, Pakhomov E, Reiss C, Meyer B (2020) Blooms of a key grazer in the Southern Ocean - an individual-based model of Salpa thompsoni. Progress in Oceanography 185:102339. doi: 10.1016/j.pocean.2020.102339

22. Harbison GR, Gilmer RW (1976) The feeding rates of the pelagic tunicate Pegea confoederata and two other salps. Limn and Oceanogr 21:4:517-528. https://doi.org/10.4319/lo.1976.21.4.0517

23. Henshke N, Pakhomov E, Groeneveld J, Meyer B (2018) Modelling the life cycle of Salpa thompsoni. Ecol Model 387:17-26. https://doi.org/10.1016/j.ecolmodel.201808.017

24. Henshke N, Pakhomov E (2019) Latitudinal variation in Salpa thompsoni reproductive fitness. Limnol Oceanogr 64:575-584. doi: 10.1002/Ino.11061

25. Igushi N, Ikeda T (2004) Metabolism and elemental composition of aggregate and solitary forms of Salpa thompsoni (Tunicata: Thaliacea) in waters off the Antarctic Peninsula during austral summer 1999. J Plankton Res 26:9:1025-1037. https://doi.org/ 10.1093/plankt /fbh093

26. Ikeda T (1974) Nutritional ecology of marine zooplankton. Mem Fac Fish Hokkaido Univ: 1-97. http://hdl.handle.net/2115/21857. Accessed October 3 2020

27. Ikeda T, Bruce B (1986) Metabolic activity and elemental composition of krill and other zooplankton from Prydz Bay, Antarctica, during early summer (November-December). Mar Biol 92:545-555

28. Ikeda T, Mitchell AW (1982) Oxygen uptake, ammonia excretion and phosphate excretion by krill and other antarctic zooplankton in relation to their body size and chemical composition. Mar Biol 71:283-298. https://doi.org/10.1007/BF00397045

29. Ivleva IV (1981) The temperature of the environment and the rate of energy metabolism in aquatic animals. Naukova Dumka Publishers, Kiev. (In Russ.).

30. Kisselev IA (1969) Plankton of the seas and continenta waters. 1. Introductory and general problems of the planktology. Nauka Publishers, Leningrad, p 658. (In Russ.)

31. Kearney M, Porter W (2009) Mechanistic niche modelling: combining physiological and spatial data to predict species' ranges. Ecol Lett 12:1-17. https://doi.org/10.1111/j.1461-0248.2008.01277.x

32. Khaylov KM, Popov AE (1983) The concentration of living weight as a regulator of the functioning of aquatic organisms. Ecology of the sea. Naukova Dumka Publishers, Kiev, pp 3-16. (In Russ.)

33. Khailov KM, Prazukin AV, Minkina NI, Pavlova EV (1999) Concentration and functional activity of living matter in condensations of different levels of organization. Successes of the Modern Biology 119:1:3-14. (In Russ.)

34. Kuz'menko LV (2004) Phytoplankton of the western part of the Bransfield Passage. Ukrainian Antarctic Journal 2:125-137. (In Russ.)

35. Loeb VJ, Santora JA (2011) Population dynamics of Salpa thompsoni near the Antarctic Peninsula: Growth rates and interannual variations in reproductive activity (1993-2009). Prog Oceanogr 96:93-107. doi:10.1016/j.pocean.2011.11.001

36. Lomakin PD, Samyshev EZ (2004) Oceanographic conditions in the area of the South Shetland Islands in March-April 1997, 1998 and their influence on krill distribution. Oceanology 44:6:882-891. (In Russ.)

37. Madin LP, Deibel D (1998) Feeding and energetics of Thaliaceae.. In: In: Bone Q (ed) The biology of pelagic tunicates. Oxford University Press, Oxford, pp $81-114$

38. Madin LP, Purcell JE (1992) Feeding, metabolism and growth of Cyclosalpa bakeri in the Subarctic pacific. Limnol a Oceanogr 37:6:1236-1251. https://doi.org/10.4319/lo.1992. 37.6.1236

39. Minkina NI (2007) Spatial variability of energetic exchange rates of zooplankton (method of evaluation). Monitoring Systems of Environment: Tools, models, monitoring: Scientific Proc Sevastopol pp318-324(In Russ.)

40. Minkina NI, Pavlova EV (1995) Daily changes in the intensity of respiration of the ctenophore Mnemiopsis leidyi in the Black Sea. Oceanology 35:2:241245. (In Russ.)

41. Minkina NI, Samyshev EZ, Chmyr VD, Seregin SA (1999) Relative evaluation of assimilation of primary production by krill, salps and bacterioplankton in Atlantic Sector of Antarctic (ASA) under the condition of mass development of gelatinous animals. Abstracts of the 2nd Int. Symp. Krill (23-27 Aug. 1999. Santa Cruz, USA). 33-35

42. Minkina NI, Samyshev EZ (2004) The specific rate of energy metabolism in Antarctic salps. Monitoring Systems of Environment. Means and monitoring: Scientific Proc. Sevastopol, pp 286-294 (In Russ.)

43. Minkina NI, Samyshev EZ (2014) Energy metabolism of the Antarctic salpa (Salpa thompsoni Foxton) in a heterogeneous oceanographic field. Monitoring the state of the Antarctic environment and ensuring the activities of national expeditions: Materials 1st Int. Scientific-Practical Conf. (May 26-29, 2014, Naroch, Belarus). Minsk: Ecological Perspective, pp 159-164 (In Russ.)

44. Pakhomov EA (2004) Salp/krill interactions in the eastern Atlantic sector of the Southern Ocean. Deep-Sea Res II 51(22-24):2645-2660 
45. Pakhomov EA, Hunt PV (2017) Trans-Atlantic variability in ecology of the pelagic tunicate Salpa thompsoni near the Antarctic Polar Front. Deep-Sea Research. Part II http://doi.org/10.1016/j.dsr2.2017.03.001

46. Pakhomov EA, Dubischar C, Strass V, Brichta M, Bathmann U (2006) The tunicate Salpa thompsoni ecology in the Southern Ocean. I. Distribution, biomass, demography and feeding ecophysiology. Mar Biol 149:609-623. https://doi.org/10.1007/s00227-005-0225-9

47. Pakhomov EA, Froneman PW, Perissinotto R (2002) Salp/krill interactions in the Southern Ocean: spatial segregation and implications for the carbon flux. Deep Sea Res II 49:1881-1907. https://doi.org/10.1016/S0967-0645(02)00017-6

48. Reinke M (1987) On the feeding and locomotory Physiology of Salpa thompsoni and Salpa fusiformis. Ber Polarforsch 36:88. (In German)

49. Pavlova EV (1975) Metabolism of Mediterranean zooplankton. Biological structure and productivity of planktonic communities of the Mediterranean Sea. Naukova Dumka Publishers, Kiev, pp 124-144. (In Russ.)

50. Popov AE (1987) On the relationship of the intensity of energy metabolism of aquatic organisms with the concentration of their mass under experimental conditions. Ecology of marine organisms. Naukova Dumka, Kiev, pp 98-104. (In Russ.)

51. Samyshev EZ (2000a) Conclusion on the state of the krill population and the pelagic ecosystem in the western region of the Atlantic part of the Antarctic in the pre-winter period of 1998. Bull Ukrainian Antarctic Center 3:231-236. (In Russ.)

52. Samyshev EZ (2000b) Salps in the Atlantic Part of Antarctic (AChA): composition, abundance, distribution. Bull Ukrainian Antarctic Center 3:237-240. (In Russ.)

53. Samyshev EZ (2002) Antarctic krill and the structure of planktonic community in its distribution area. The 2nd ed. (expand.) Nauka Publishers, Moscow

54. Samyshev EZ, Bibik VA, Savich MS, Grishin AN, Okanev OA, Alekseenko VR (1997) On the state of the krill population and pelagic ecosystem in the region of the Scotia Sea. Bul Ukrainian Antarctic Center 1:132-136. (In Russ.)

55. Samyshev EZ, Lushov Al, Efimov ES (1980) About the change of a specific rate of energy metabolism of hydrobionts in the process of adaptation to experimental condition (on an example of Idotea baltica basteri from the Black Sea). Hydrobiol J 6:94-96. (In Russ.)

56. Schwarz SS, Pyastolova OA, Dobrinskaya LA, Runkova GG (1976) The effect of group in populations of aquatic animals and chemical ecology. Nauka Publishers, Moscow, p 151. (In Russ.)

57. Scolardi KM, Daly KL, Pakhomov EA, Torres JJ (2006) Feeding ecology and metabolism of the Antarctic cydippid ctenophore Callianira antarctica. Mar Ecol Prog Ser 317:111-126

58. Swadling KM, Ritz DA, Nicol S, Osborn JE, Gurney LJ (2005) Respiration rate and cost of swimming for Antarctic krill, Euphausia superba, in large groups in the laboratory. Mar Biol 146:1169-1175

59. Tilman D, Hillerislambers J, Harpole S, Dybzinski R, Fargione J, Clark C, Lehman C (2004) Does metabolic theory apply to community ecology? It's a matter of scale Ecology 85:1797-1799. JSTOR, . Accessed 13 October 2020

60. Vinbeg GG (1956) Energetic metabolism and food requirement of fishes. Academy of Sci. of Belarussia Publishers, Minsk: 251 p. (In Russ.)

61. Vinberg GG (1960) Primary production of waters. Academy of Sci. of Belarussia Publishers, Minsk: 330 p. (In Russ.)

\section{Figures}




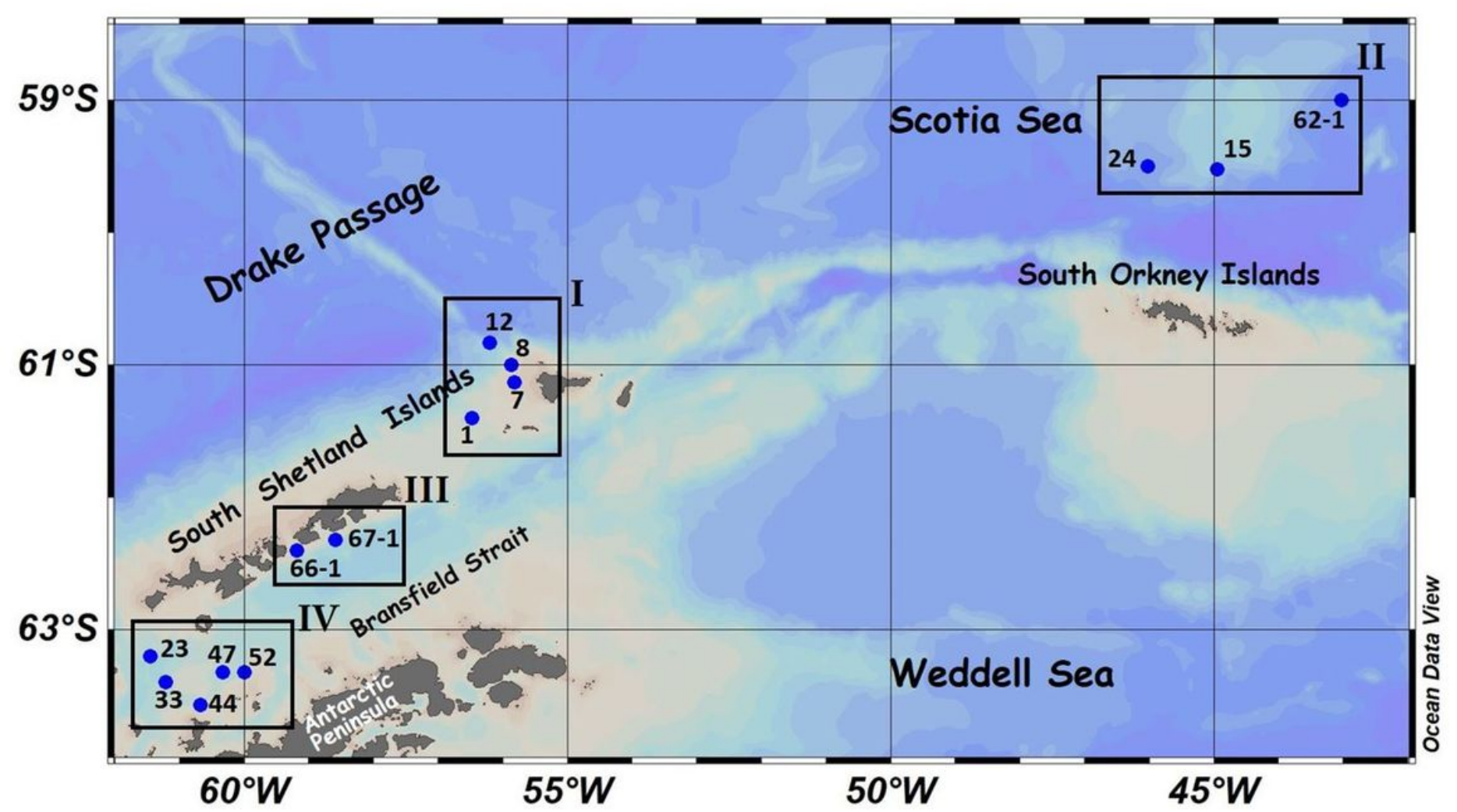

Figure 1

Station positions of Salpa thompsoni respiration rate measurements during 1998 near the Elephant Island (I), north of the South Orkney Islands (II) and in the vicinity of the King George Island (III), and during 2002 in the Bransfield Strait (IV). 


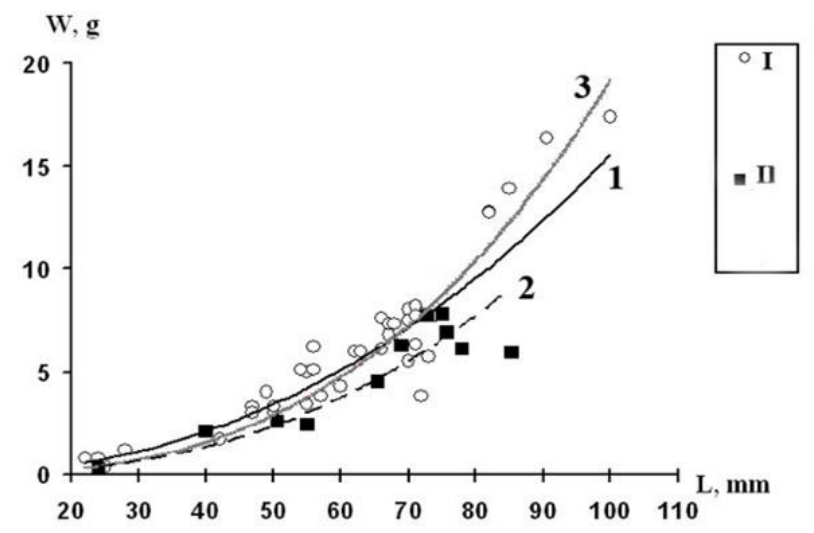

a

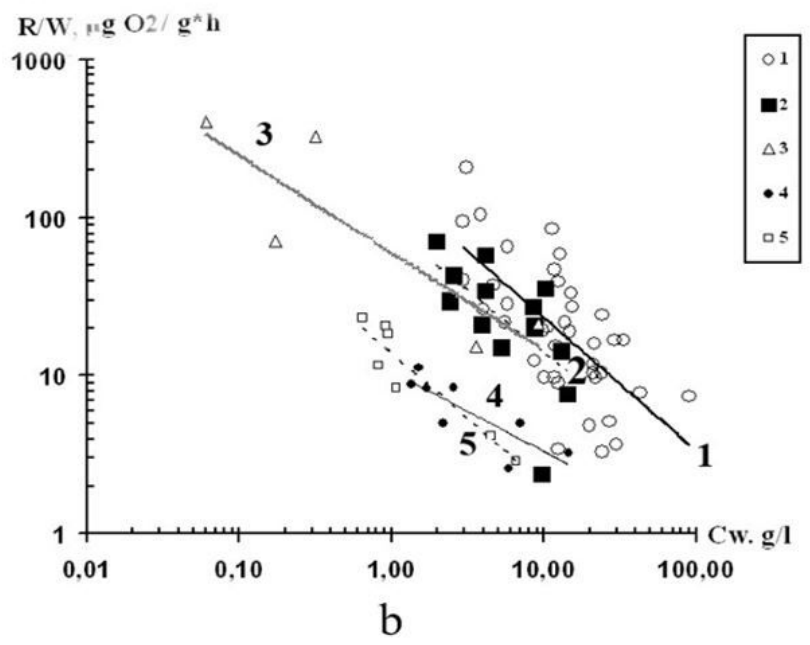

\section{Figure 2}

(a) Wet weight of salps against the body length. I: solitary forms, Il: colonial forms; 1 : $W=0.006 L^{2.19}, \mathrm{~N}=41, \mathrm{r}^{2}=0.897$ (own data); 2 : $W=0.00016 L^{2.53}, \mathrm{~N}=13$, $r^{2}=0.93$ (own data); $3: W=0.000634 L^{2.34}, N=60, r^{2}=0.94$ (from Anninsky and Shchepkina (2004)), the correlation is found for both forms of salps. (b) Specific respiration rates $\mathrm{R} / \mathrm{W}$ of salps against the live weight concentration in the respirometers at $3^{\circ} \mathrm{C} .1: R / W=161.22 C_{W}{ }^{-0.84}, \mathrm{r}^{2}=0.447$ (own data); $2: R / W=85.38$ $C_{w}{ }^{-0.91}, \mathrm{r}^{2}=0.59$ (own data); 3 : calculated by the authors according to Pavlova (1975), $R / W=60.2 C_{w}{ }^{-0.62}, \mathrm{~N}=20, \mathrm{r}^{2}=0.747 ; 4$ : calculated by the authors according to Ikeda (1974) for five species of aggregate tunicates: $R / W=7.23 C_{W}{ }^{-0.69}, \mathrm{~N}=7, \mathrm{r}^{2}=0.876$; and 5 : for solitary forms of three salp species, $R / W=10.63 C_{W}^{-0.51}, \mathrm{~N}=8, \mathrm{r}^{2}=0.680$. 

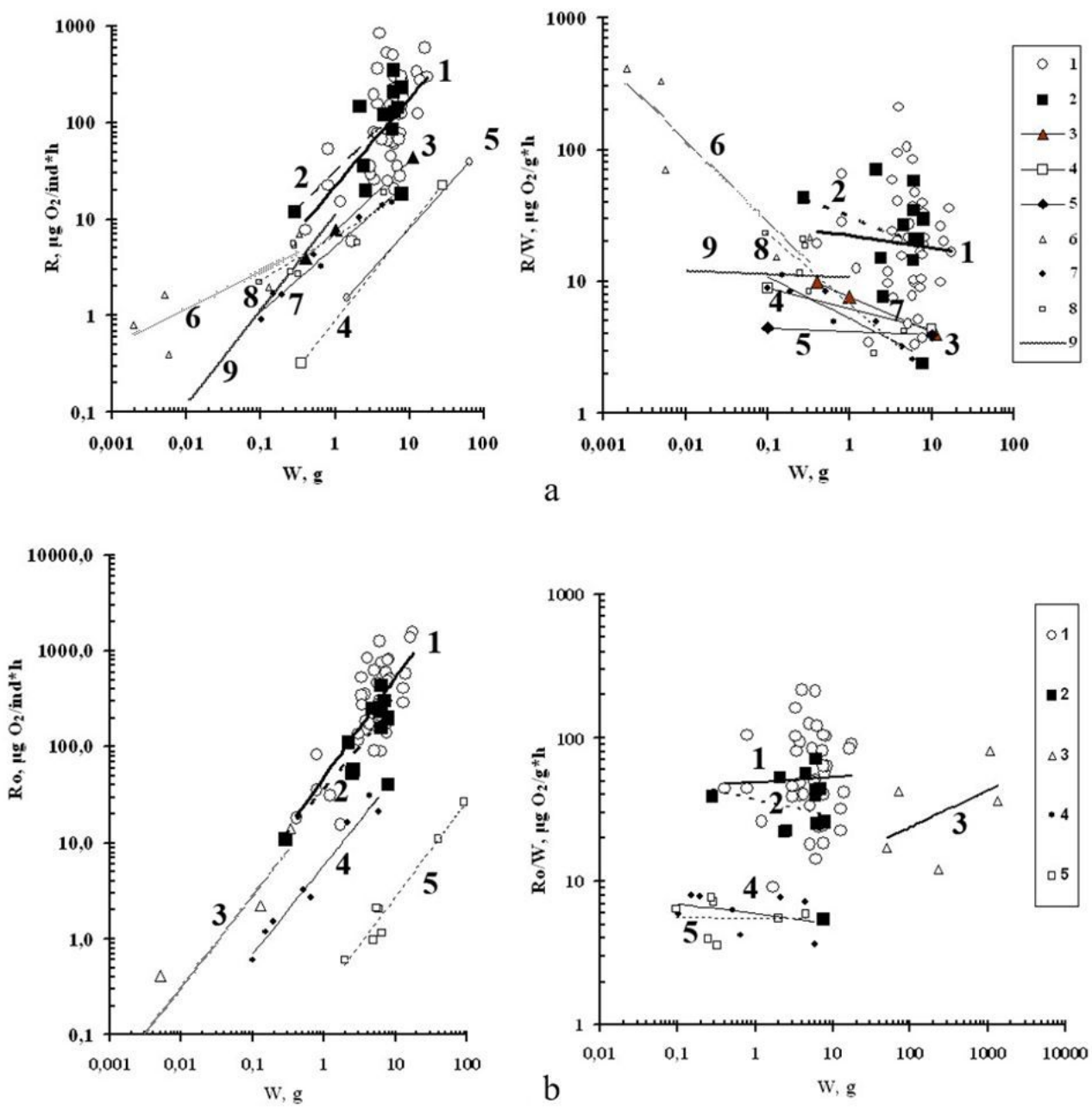

Figure 3

The energy metabolism reduced to $3^{\circ} \mathrm{C}$ in salps from different regions of the World Ocean as a function of the body weight. (a) Variable weight concentration $C_{W}$ in the experiments; 1 and 2: our own data for the solitary and aggregate forms; 3: data for Salpa thompsoni (Ikeda and Mitchell 1982); 4 and 5: data for the aggregate and solitary forms of $S$. thompsoni (Igushi and Ikeda 2004); 6: data for two species of Mediterranean salps by Pavlova (1975); 7 and 8: data for solitary and aggregate tropical tunicates by Ikeda (1974); 9 : data for two species of Mediterranean salps by Abolmasova (1978). (b) $C_{W}=C_{0}=3 \mathrm{gWW} \cdot \mathrm{I}^{-1} ; 1$ and 2: our own data for the solitary and aggregate S. thompsoni; 3: data for two species of Mediterranean salps (Pavlova 1975); 4 and 5: data for solitary and aggregate tropical tunicates (Ikeda 1974). The respective fit equations are given in Table 2. 


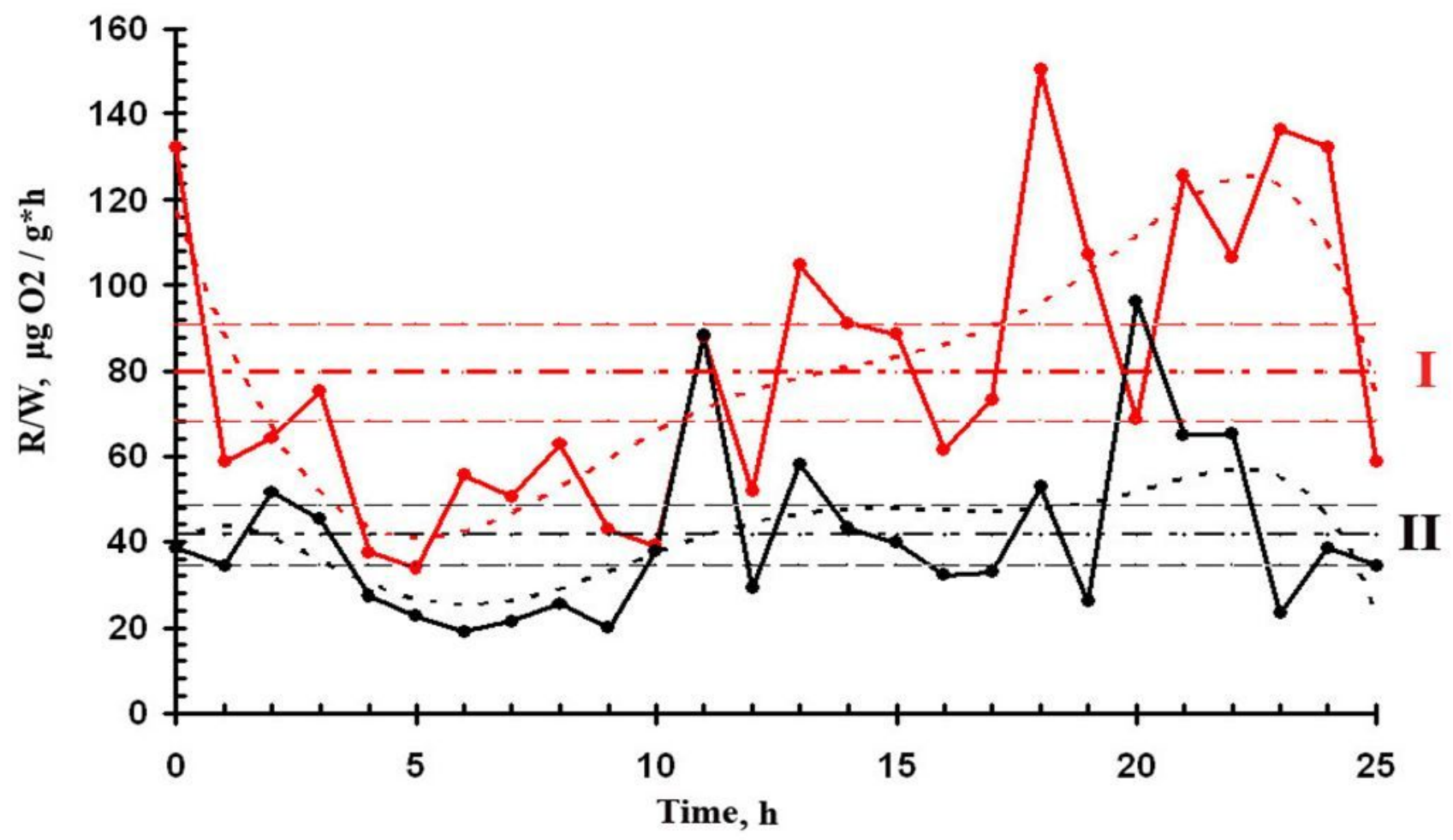

Figure 4

Circadian rhythm of specific respiration rates in the solitary (I) and aggregate (II) forms of Salpa thompsoni. Dotted lines are polynomial trends of the sixth degree; dash-dot lines are the daily average for each form and dashed lines represent the $90 \%$ confidence intervals of the average daily values. 


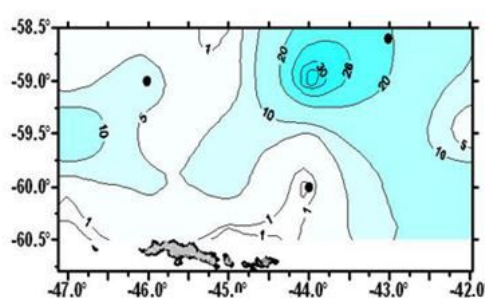

a

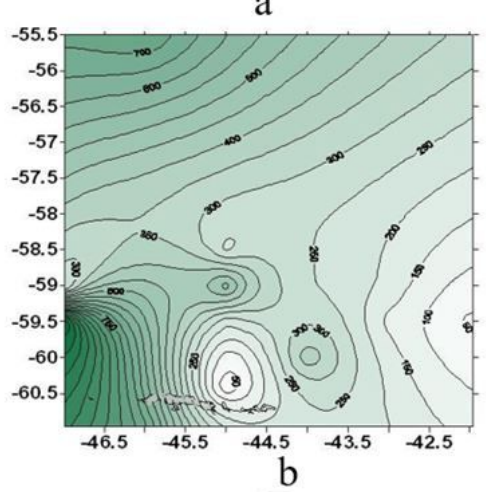

$\mathrm{g} \cdot \mathrm{m}^{-3}$

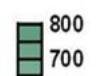

\section{$日_{700}^{800}$}

600
500

-400

300

200
100

$\mathrm{mg} \cdot \mathrm{m}^{-3}$

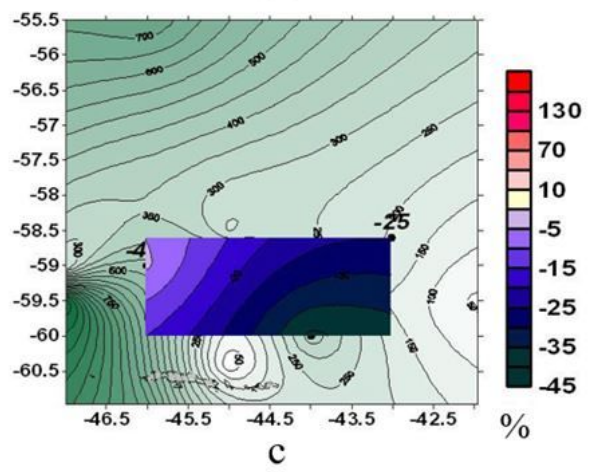

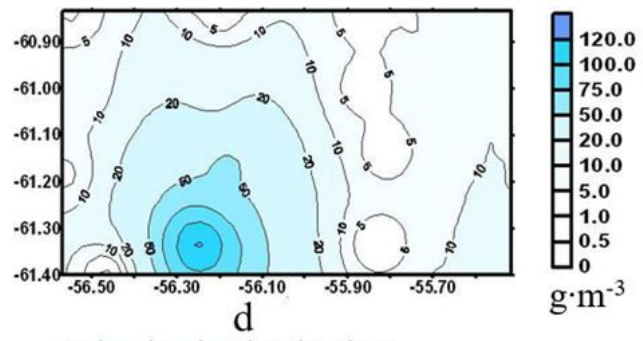
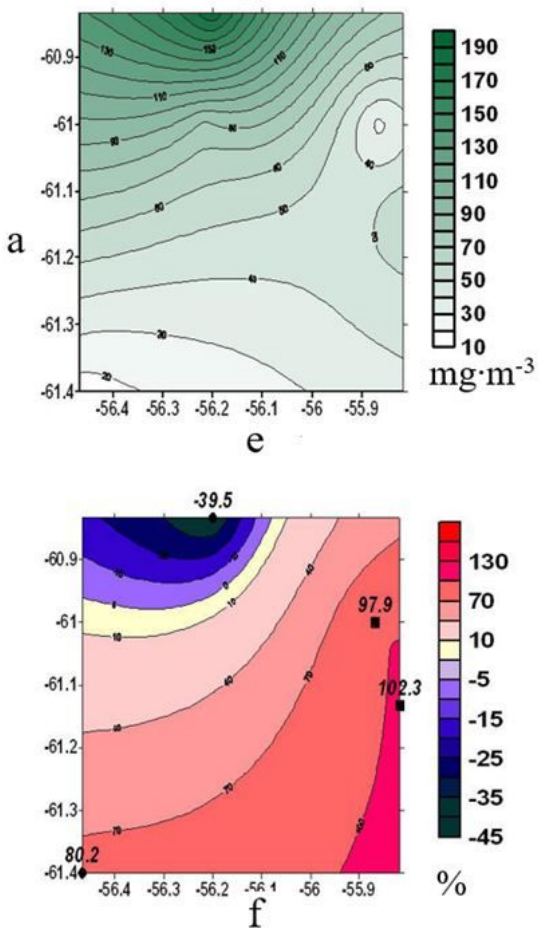

\section{Figure 5}

Salpa thompsoni metabolic rate values as a function of the food availability in the 0-100 m layer during March 1998. Left panels: north of the South Orkney Islands, right panels: in the vicinity of the Elephant Island. (a), (d) biomass of salps (Samyshev 2000b); (b), (e) distributions of the phytoplankton biomass according to Yu.V. Bryantseva (unpublished data); (c), (f) as above with superimposed inserts showing the spatial variability of the salp metabolic rates as deviation (in \%) from the "statistical norm". 


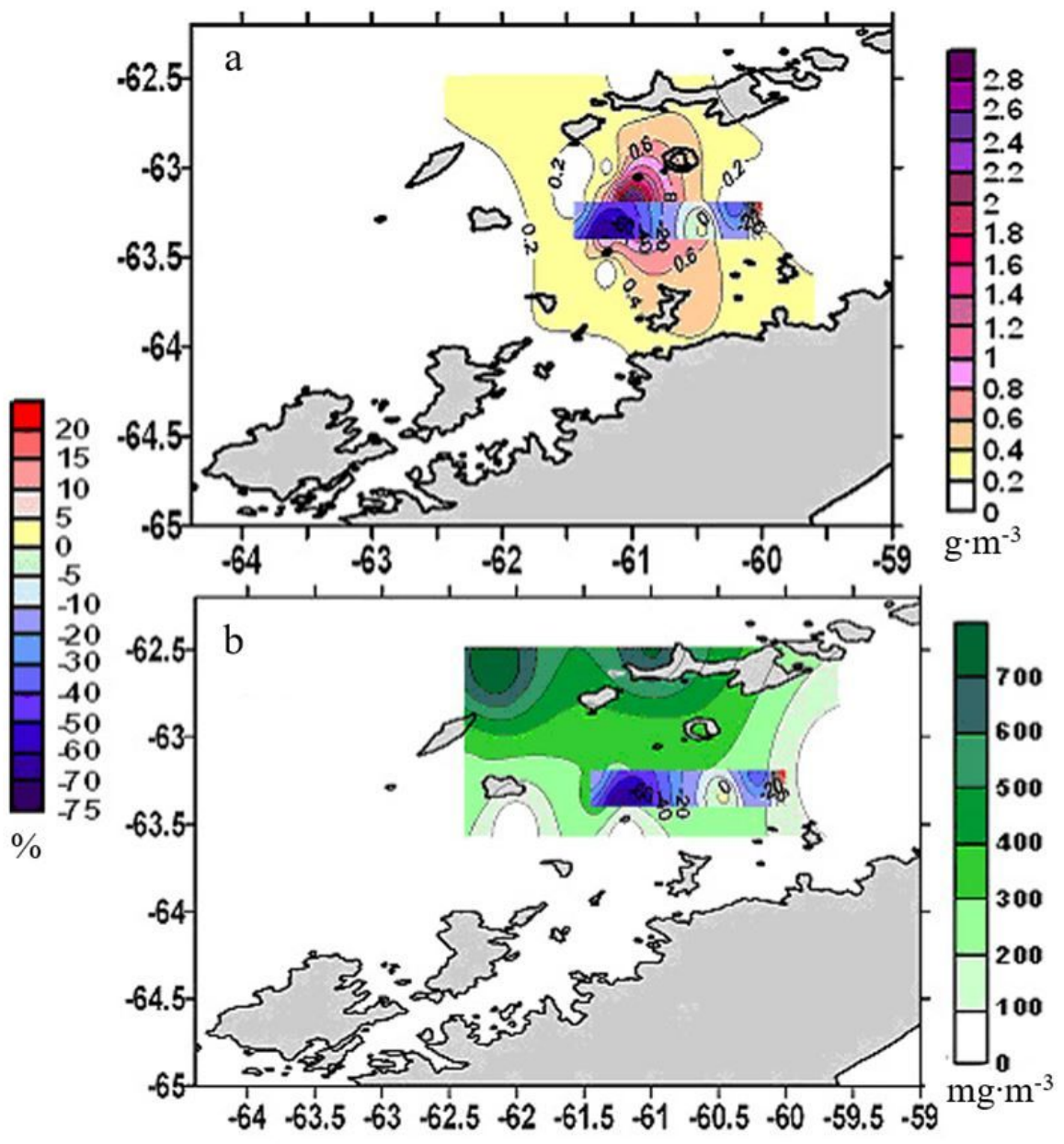

Figure 6

Salpa thompsoni metabolic rates as a function of the food availability in the 0-100 m layer in the Bransfield Strait during March 2002. (a) the salp biomass distribution according to Minkina and Samyshev (2014); (b) the phytoplankton biomass distribution according to Kuz'menko (2004). The superimposed inserts show the spatial variability of the salp metabolic rates as deviation (in \%) from the "statistical norm". 